\title{
ALL 3 LINC LEVELS
}

Acosta, J. (1981-present). The westcoast reader. Langley, B.C.: B.C. Ministry of Advanced Education/Capilano College. Free.

ESL literacy; life skills and community resources; citizenship; regional; illustrations

For adult learners in B.C., this monthly newspaper features brief, simplified versions of major news stories, descriptions of social or government services, and stories of popular interest. Material is presented in large print; accompanied by photos, point-form summaries, and illustrations; and graded for language (beginner or intermediate) proficiency.

Acosta, J. (1987). Coast-to-coast reader. Vancouver: Douglas \& McIntyre. 63 pages. $\$ 9.95$.

ESL literacy; illustrations

Fifty-two one-page articles about Canadians, Canada, and daily life in Canada are illustrated with pictures and drawings. Straightforward language conveys information about a variety of people, concepts, situations, and places.

Alberta Advanced Education. (n.d.). English express. Newspaper \& teacher's notes. Edmonton: Alberta Advanced Education. Free.

ESL literacy; culture; illustrations

The teacher's notes accompanying this monthly newspaper for adult ESL learners provide activities and further information 
about the content of the paper. The newspaper has four printed pages, and sometimes inserts on topics of special interest. Blackand-white photographs, illustrations, and syndicated cartoons supplemented the articles, which are graded for linguistic difficulty. Regular features are "Healthline" and a crossword puzzle.

Anderson, S. \& Sorensen, M. (1981). Writing Canadian English: Beginning, Teacher's handbook \& Student workbook. Calgary: Detselig. $60+100$ pages. Anderson, S., \& Roth, K. (1983). Writing Canadian English: Intermediate, Teacher's handbook, \& Student workbooks. Calgary: Detselig. $102+72+100$ pages. Beginning Teacher's Handbook \$5.95; Student Workbook \$8.95; Intermediate Teacher's Handbook and Student Workbook \$8.95.

ESL literacy; citizenship; life skills; teacher's manual; workbooks; illustrations

Writing activities are organized to focus on grammar points, which are explained in the teacher's handbook. In each of the beginning level units, short answer and sentence manipulation exercises are followed by model compositions on Canadian topics; free compositions based on the model are also assigned. The student's workbook has space for writing answers to exercise questions and final drafts of compositions. Crossword puzzles and games are included in some units. At the intermediate level, one teacher's handbook and student workbooks (at two levels of difficulty) continue the writing practice introduced in the beginner text. Grammar points are illustrated in the context of topics, such as banking, health, taxes, or citizenship. There are exercises in sentence completion, short answer, and paragraph writing. Oral drills are provided in the teacher's handbook, and supplemental activities focus on discussion. 
Au, G., Vien, D., Quan, B., Chen, T., Chuit, T., Chan, K., \& Chang, W., (\& McGee, D. (Ed.).). (1982). A new life in Canada. Vancouver: Vancouver Community College and Vancouver Public Library. 23 pages. $\$ 3.50$.

ESL literacy; life skills; illustrations

Beginning students of ESL wrote about their own lives in Canada in this beginning reader, documenting experiences such as losing a purse and learning to drive, as well as family activities, work skills, and education. Large type and photographs are featured.

Avery, P. and Ehrlich, S. (Eds.). (1987). The teaching of pronunciation: An introduction for teachers of English as a second language. Special issue of TESL Talk, 17. Toronto: Ontario Ministry of Citizenship. 184 pages. $\$ 3.50$.

teacher reference; speaking/conversation; annotated bibliography

An introduction to the theory and teaching of pronunciation, this volume includes 10 original articles which describe the English sound system and common pronunciation problems of ESL learners of various language groups, offering practical advice for teachers to help students. Phonetic transcriptions describe Canadian English.

Avery, P., \& Ehrlich, S. (1992). Teaching American English pronunciation. Oxford: Oxford University Press. 254 pages. $\$ 29.50$.

teacher reference; annotated bibliography

Intended as both a teacher textbook and reference, this three part book provides a comprehensive introduction to teaching the 
pronunciation of North American English. Part One introduces the sound system of English. It contains useful diagrams indicating the places of articulation for the various speech sounds of English. In Part Two, specific pronunciation problems of 14 language groups are identified and suggestions for correction are offered. Part Three covers a range of practical issues from teaching techniques and classroom exercises to syllabus design.

Barndt, D., Belfiore, M., \& Handscombe, J. (1985, video 1988). English at work: A tool kit for teachers. North York, Ont.: CORE Foundation. $\$ 225.00$.

teacher reference; English for work; life skills; audiotape; photographs; 30 cartoon cards; sample student history book; photo-poster; videocassette tutorial; plastic folder

Language activities in this multi-media teacher's module are based on the daily working lives of immigrants in urban Canada. The teacher is described as a participant researcher who reacts to the students' experiences and needs in designing an appropriate curriculum. The content of the five units (histories of immigrant workers, industrial and service sector jobs, work relationships, working conditions, and home and community life) are applicable to a variety of workplaces. The teacher's manual encourages progressive development of curricula, emphasizing activities like listing work-related activities and equipment, charting communication flow maps, outlining job tasks, comparing jobs in Canada and their homelands, and mapping the local neighbourhood. Student worksheets for these activities are included. The video is an introduction to the "tool kit".

Barndt, D., Cristall, F., \& Marino, D. (1982). Getting there: Producing photostories with immigrant women. Toronto: Between the Lines. 110 pages. $\$ 10.95$. 
ESL literacy; teacher \& adult student guides; illustrations; poster insert

This teacher resource book shows how and why photostories can be produced to foster language and literacy learning. Seven chapters introduce 4 kinds of material: 2 essays focusing on employment and advertising as contexts for the photostories, an explanation of the production of photostories, 2 examples of photostories, and a discussion section with suggested activities. "Collective" learning is emphasized, with students directing much of the process.

Bates, S. (1990). Amazing! Canadian newspaper stories. Instructor's manual and Student's book. $201+178$ pages. Scarborough: Prentice-Hall Canada Inc. Student's book $\$ 17.00$.; Instructor's manual $\$ 32.67$.

ESL literacy; general language study; newspaper stories; illustrations; quiz and answer keys.

This reading/language textbook focuses on developing reading skills, but listening, speaking and writing activities are incorporated into each of the twelve chapters. Twelve newspaper stories from across Canada are featured, teaching students about the country and Canadian culture. The original stories in the Instructor's manual have been rewritten in the Student's book to accommodate the learners' proficiency level. The Instructor's manual includes supplementary materials to help teachers adapt the stories to the particular needs of their students. Answers to the quiz questions are found in the Teacher's and Student's book. 
Bates, S. (1993). Amazing! Interviews and conversations. Instructor's manual and Student's book. $290+130$ pages. Scarborough, Ont.: Prentice-Hall Canada Inc. Student's book $\$ 18.00$; Instructor's manual $\$ 40.00$; audiocassettes (4) \$93.27.

speaking/conversation; citizenship; illustrations; answer key

A companion text to Amazing! Canadian newspaper stories, this book contains interview topics related to the newspaper stories contained in the earlier text. Each of the fourteen chapters is organized into three sections. In Section 1, facts on Canadian culture are presented followed by authentic interviews with Canadians and a speaking activity designed to generate intercultural discussion. The second section features an audiotaped interview or conversation about a newspaper story with accompanying illustrations. Included in the last section are audiotaped conversations and follow-up speaking activities. The Instructor's manual contains transcripts of the interviews and conversations, instructor's notes, supplementary materials and an answer key.

Bell, J. (1988). Teaching multilevel classes in ESL. San Diego: Dormac. 165 pages. $\$ 18.50$.

teacher reference; illustrations; sample lessons \& exercises; bibliography

Bell discusses a wide range of practical pedagogical considerations in teaching classes of adult students with different levels of ESL proficiency. The book suggests techniques appropriate for curriculum planning, classroom instruction, and student activities in this situation. Bell first identifies unique factors in multilevel classrooms. She then describes, in casestudy fashion, a typical teacher's course planning; numerous methods for student assessment; and diverse ways to organize whole class, group, individual, and self-access learning tasks. 
A sample lesson sequence closes the book, along with a brief annotated bibliography to guide further reading.

Bell, J. (Ed.). (1990). ESL literacy. Special Issue of TESL Talk, 20(1). Toronto: Ontario Ministry of Citizenship. 340 pages. $\$ 5.00$.

teacher reference; ESL literacy; bibliographies

An authoritative collection of articles on the theory and pedagogical practices of adult ESL literacy education, this volume covers various issues and themes of relevance to teachers, curriculum organizers, and educators. The first two sections of the book feature 17 chapters by Canadian and international researchers defining educational and theoretical issues central to learning and teaching literacy to adults in a second language. The second section includes 16 chapters about specific teaching approaches, materials, and classroom tips. The final two sections consider student assessment and curriculum planning.

Bell, J., \& Burnaby, G. (1984). A handbook for ESL literacy. Toronto: OISE Press, Hodder \& Stoughton. 140 pages. $\$ 13.95$.

teacher reference; ESL literacy; sample materials; illustrations; bibliographies; appendices

This book orients teachers to issues, instructional approaches, and materials relevant to literacy learning and development among adult ESL students. After considering the situations and unique learning needs of these students, the book details principles for course organization, the teaching of pre-literacy skills, initial reading and writing lessons, multi-level groups, and student assessment. A variety of teaching practices, lesson 
sequences, and visual materials are described. Appendices cite common syllable patterns and frequent words in English.

Berish, L., \& Thibaudeau, S. (1992). Canadian concepts 1. Teacher's Manual, Activity Book. $134+163$ pages. Canadian concepts 2. Teacher's Manual, Activity Book. $140+166$ pages. Canadian concepts 2 . Teacher's Manual, Activity Book. $159+159$ pages. Canadian concepts 3. Teacher's Manual, Activity Book. $166+155$. Canadian concepts 4 . Teacher's Manual, Activity Book. $155+150$. Scarborough, Ont.: Prentice-Hall Canada Inc. Teacher's Manual \$30.00; Student Workbook \$15.00; Audiocassettes $\$ 30.00$

general language study; life skills; series; grammar; audiocassettes; videocassettes

Each book in the series has its own Teacher's Manual that includes instructions, suggestions, answers, tapescripts, dictation and pronunciation exercises and student worksheets. Each activity book includes pre-activities, core activities, review and recycle activities and real-life application activities. Student workbooks are organized by life skills which help integrate students into the Canadian community. Themes are recycled with increasing complexity. All skills, along with supplementary grammar is integrated into each unit. A video program is introduced into Canadian concepts 4 . Three videos (Farming, The Four Seasons: Spring and Families of the world: Mexico) can be obtained from the National Geographic Society in Mississauga, Ontario. The titles of the videos match the headings of the activities. 
Brock, P., Houghton, W., Hlodan, O., \& White, O. (1976). Module: English as a second language, Book 1, modules 1, 2, 3. 157 pages. (1979). Workbook 1, modules 1, 2, 3. 97 pages. (1976). Book 4, modules 10, 11, 12 . 175 pages. Workbook 4 , modules $10,11,12$. 80 pages. (1979). Book 7 , modules $19,20,21$. 70 pages. (1980). Workbook 7 , modules 19, 20, 21. 166 pages. Montreal: Les Editions des Ateliers, Inc., Centre Educatif et Culturel Inc. Book 1, 2, 3 \$13.95; Book $4 \$ 14.15$; Workbook 1-6 \$6.75; Workbook $7 \$ 8.10$; Cassettes $\$ 309.75$.

general language study; series; regional; text and workbook; illustrations; audiocassettes; tests

The texts and workbooks in this series focus on reading, writing, and speaking, including intermediate and terminal objectives for these three skills in each module. Earlier modules emphasize speaking skills. Workbooks have reading texts, written exercises, diagnostic tests, and correction keys. Recorded material has dialogue, expansion drills, conversations, words and expressions, pronunciation examples, reading aloud, and tests. Some of the books have bilingual instructions (French and English), designed for English courses in Quebec. Modules begin with a presentation and continue with a dialogue, sentence building, expansion drills, and other language-oriented tasks, organized by grammar points.

Burnaby, B. \& Cumming, A. (Eds.). (1992). Socio-political aspects of ESL in Canada. Toronto: OISE Press. 334 pages. $\$ 36.50$.

teacher reference; ESL literacy; citizenship; bibliographies

The 21 chapters in this book address various policy, curriculum, theoretical, and pedagogical issues related to socio-political 
concerns in ESL education in Canada. Research studies focus on national surveys, case studies of particular learner groups or educational settings, demographic data, or recurring problems in educational programs such as participation by immigrant women, literacy, coordination of services, testing, or appropriate program supports.

Butovsky, L., \& Podoliak, E. (1984, 1985). Welcome to Canadian English: A basic handbook for students living in Ontario, Part 1, \& 2. $132+274$ pages. (1985). A Teacher's guide: Welcome to Canadian English, Part 1 and part 2. 46 pages. Toronto: Ontario Ministry of Citizenship. Student Book $\$ 3.00$; Teacher's Guide $\$ 3.00$.

general language study; life skills and community resources; regional; teacher's guide; illustrations; answer key

The units in the two parts of the student's book are organized by themes, which feature the same characters in a variety of everyday situations. Grammar is isolated from the communicative practice of the skill-based activities, many of which are appropriate for non-literate students. Sections of useful information about medical care, human rights, employment standards, and other social issues extend each theme for more advanced students. An appendix of irregular verbs is included. The teacher's guide is organized by the different activity headings in the student book, and includes a summary of the purpose of each type of activity, teaching suggestions, briefly annotated references, and a list of contents in the student book. The material is designed for recent immigrants to Ontario.

Butovsky, L., \& Creatore, C. (1988, 1989). Classics in photostories series, (1988). The gift of the Magi. 58 pages. (1988). The doorman. 71 pages. (1989). Jealousy. 65 pages. San Diego, California: Dormac Inc. Price: Booklets \$9.95; audiocassette $\$ 24.95$. 
general language study; series; photographs; audiocassettes

Classics in photostories is a series in which each book presents a dramatization of a story through photographs and simplified language. Audiocassettes available for each book provide natural language in dialogue, narrative and discussion form and listening activities. Each book contains a story along with photographs and comprehension, vocabulary, speaking, listening and discussion activities. Also included is a grammar section and a section consisting of language games, puzzles and other activities related to the story. An answer key and tapescript accompany each book.

Cameron, J., \& Derwing, T. (1991). The Environment and you. 114 pages. Who cares about the environment? 106 pages. Calgary. Alberta: Detselig Enterprises Ltd. \$9.95.

ESL literacy; workbooks; teacher's guide

These two workbooks form self-contained units on environmental issues. Each workbook contains suggestions for supplementary activities and materials for the teacher, prereading questions and vocabulary, reading on an environmental theme, comprehension and discussion questions and classroom interactive pair and group activities. References are included.

Canadian Public Health Association. (1990). Learning about AIDS program. Ottawa, Ont.: Canadian Public Health Association. Free.

Teacher reference; life skills; student booklet; teacher's guide; posters; pamphlets

The AIDS awareness programme includes pamphlets, booklets, a student booklet and teacher's guide and a guide for parents on 
talking with their children about AIDS. Although the student booklet and teacher's guide are geared to children, they provide background information for both teachers and students. The guide for parents provides basic information about AIDS and contains suggestions on how to discuss these facts with their children.

Carver, T., Fontinos, S., \& Cooper, C. (1993). A Canadian conversation book Book 1. Scarborough, Ontario: Prentice-Hall Canada Inc. 166 pages. $\$ 14.00$.

speaking/conversation; vocabulary; illustrations; maps; photographs; appendix

This book contains six conversation units organized by theme and introduces vocabulary at a basic level needed for everyday conversation. Each unit contains questions, illustrations, and pictures to motivate oral production. The appendix introduces students to the Roman alphabet and contains maps of the world and a short selection of Canadian songs.

Central Newfoundland Regional College of Applied Arts, Technology and Continuing Education. First time readers. Grand Falls-Windsor, N.F.: Central Newfoundland Regional College of Applied Arts, Technology and Continuing Education. Free within Newfoundland.

ESL literacy; citizenship, life skills; regional; newspaper; photographs; illustrations

Published monthly, First time readers contains articles on issues relevant to Newfoundland and Canada. As the intended audience is people wanting to improve their reading skills, stories are written in plain English for easy reading. The newspaper covers such topics as sports, parenting, employment, health care, government, Canadian holidays and customs, and housing. 
Charon, M. (1989). Worlds apart: New immigrant voices. Winnipeg: Cormorant Books. 428 pages. $\$ 37.95$.

Teacher reference; anti-racist education

Immigrants tell their stories about the difficulties of settlement and integration in Canada through interviews, short stories, poems, reflections and personal histories. The book provides a source of information to help teachers understand the experiences of the newly arrived individuals to Canada.

Chin, F., \& Bowers, B., (Eds.), \& Creary, M. (exercises). (1980). Stories for advanced beginners: $A$ reader and textbook for the adult English language student. 155 pages. Chin, F. (Ed.) (\& Dragman, J., \& Chin, F., (exercises)). (1988). Stories for advanced beginners, Book 2: A reader and workbook for adult English as a second language students. 179 pages. Vancouver: Vancouver Community College. $\$ 10.00$.

ESL literacy; vocabulary; general language study; regional; illustrations

Short reading passages on a variety of daily activities are followed by new vocabulary lists, questions for reading comprehension, and exercises focusing on word use, meaning, and syntax. Book 2 adds pre-reading activities based on illustrations, vocabulary lists, and questions for discussion. Canadian content is emphasized in brief reading passages, focusing on locations in B.C. Exercises that follow the reading passages focus on comprehension, sentence completion, grammar, word meaning and use, and short writing assignments. 
Clandfield, S. (1990). All ears: A guide to listening kits for ESL instructors. Toronto: Toronto Board of Education. 60 pages. $\$ 10.00$.

teacher reference; bibliography

This four-part catalogue provides bibliographic information and a detailed description of the characteristics and content of listening kits produced in Canada, Great Britain and the United States. The characteristics listed include level of difficulty, linguistic approach, skills focussed on, gender variation of voices, cultural/racial bias, Canadian content, accents, registers and the nature of the taped material.

Clark, C., \& Pitton, C., (illus. by Kluthe, K.). (n.d.). Card games for infinite language. Vancouver, B.C.: Canada Language Centre. $\$ 14.00$.

speaking/conversation; games; illustrations

Twelve card games focus on functions of language such as requesting, borrowing, offering, inviting, and on situations such as finding a place to live, hobbies, and everyday activities. Three decks of illustrated cards are included in each package, allowing up to 15 students to participate. Rules are similar to "Go Fish", in which students match pairs by engaging fellow players in a brief dialogue based on the illustration. Teacher's notes give information about the language focus, abbreviations on the cards, and variations for difficulty. Each game takes about 15 minutes.

Cohen, K., \& Desmet, P. (1989). Links: A new language, a new country. Scarborough, Ont.: Prentice-Hall Canada. 223 pages. Workbook \$10.97; Cassettes \$15.25.

general language study; teachers' guide; audiocassettes; 
photographs; exercises

Emphasizing a communicative approach to language learning for recent arrivals in Canada, Links offers exercises based on continuous stories about six main characters. Stories focus on adult students, personal information, family trees, exchanging news, weekend plans, and class get-togethers. Each of ten units includes reading, writing, listening, and speaking exercises which can be adapted to varied learning styles and proficiency levels. Idioms, personal letters, discussions, comprehension questions, listening for specific information and tenses, and guided conversations are featured in the exercises.

Crean, M. (Ed.). (1989). ESL and citizenship, Special issue of TESL talk, 19(1). Toronto: Ontario Ministry of Citizenship. 158 pages. $\$ 4.00$.

teacher reference; citizenship; figures; photographs

The 18 brief papers prepared for this volume discuss ESL teaching for Canadian citizenship. Issues include appropriate and exemplary instructional materials; the politics and philosophy of citizenship; students' learning goals; curriculum content and organization; government and community policy; teachers' roles; intercultural and bilingual factors; teacher training; literacy; and legal perspectives. 
Crean, M., \& Unda, J. (1987). Citizenship ESL/literacy materials: Unit 1 Applying for citizenship. 51 pages. Unit 2 Geography. 49 pages. Unit 3 Government. 77 pages. Unit 4 Becoming a citizen. 62 pages. Unda, J. (1988). Teacher's guide. 48 pages. Toronto: Ontario Ministry of Citizenship. 4 Units $\$ 2.50$; Teacher's Guide \$1.50.

citizenship; ESL literacy; regional; teacher's guide; illustrations; audiocassettes; appendices

Information and exercises in these 4 booklets prepare students for citizenship hearings in Ontario. Language activities aim for developing literacy skills, beginning with students' oral proficiency, then reading and writing skills. Pair and group activities focus on speaking/listening, interpreting graphics, and language experience writing. Authentic materials, such as letters, notices, and forms used in citizenship procedures, are reproduced in the students' workbooks. The teacher's guide includes notes for each of the units, background information on ESL/literacy courses, suggestions for program planning, and methods of teaching each type of activity. Appendices list citizenship requirements, resources, and contents of each unit.

Cunningham, H., \& Rabinowitz, M. (n.d.) Citizenship: An English as a second language workbook for beginners. Community Survival Skills Series. Vancouver: Vancouver Community College. 83 pages. $\$ 7.50$.

citizenship; life skills; regional; illustrations

Steps from the application to the oath of citizenship are outlined. Explanations focus on information new Canadians are expected to know about the political and economic characteristics of the regions and provinces, and the federal, provincial, and municipal systems of government. Specific questions about British Columbia are included.

TESL CANADA JOURNAL/REVUE TESL DU CANADA 
Cunningham, H., Rabinowitz, M., \& Yee, S. (\& Watson, R. (Ed.).). (1983). Your home: An English as a second language workbook for beginners. Vancouver: Vancouver Community College. 38 pages. $\$ 3.25$.

life skills; vocabulary; illustrations

This workbook, initially developed to accompany television broadcasts, was revised for independent use. Exercises (short answer, word, and sentence-completion), dialogues, and vocabulary focus on the home.

Danesi, M. (1985). A Guide to puzzles and games in second language pedagogy, Language and Literacy Series. Toronto: OISE Press. 56 pages. $\$ 7.00$.

teacher reference; bibliography; illustrations

The use of 3 types of puzzles for language teaching are described: discrete-point, which promote practice of specific language points; global, which allow practice of overall language; and interactional, which involve more than one learner. Along with instructional objectives, techniques for constructing model puzzles and games are given. Multilingual examples are featured.

Davis, S., (Ed.). (1988). Partners at school: $A$ handbook on how to involve Indian and Metis parents in school activities. Regina: Saskatchewan Education. 44 pages. $\$ 1.00$.

teacher reference; anti-racist education; native education; illustrations; bibliography

This book is centered around parent teacher communication. Its four major chapters include 1) race, education and you; 2) 
parental involvement: some questions and answers; 3) what to do when parents become involved; and 4) policy-making and parental involvement.

De Franceschi, M. (1982). Stories about real people...Part one: Another land - another laugh, "Stories only" edition. 40 pages. $A$ graded reader for students of English with exercises for conversation and study. 149 pages. (1986). Stories about real people...Part two: 'A new environment: change and adjustment'. 64 pages. Windsor, Ont.: Mardan. Part 1 Stories \$7.50; Part 1 Stories and Exercises \$13.75; Part 2 Stories \$5.95.

ESL literacy; illustrations

Stories in these books are based on real-life situations, often embarrassing or humorous, without reference to any specific language or cultural group. Part One's stories focus on incidents caused by misunderstanding the social rules or the language of an English speaking culture. In Part Two the stories centre more on cross-cultural confusions. The stories are followed by discussion questions and preceded by illustrations. Vocabulary and sentence structure exercises accompany the second edition of Part One.

Dragman, J. (1983). Orientation to Vancouver. Vancouver: Vancouver Comunity College. 117 pages. $\$ 6.00$.

life skills; illustrations; teacher guide; regional

This orientation guide focusses on pre-literacy skills (especially addresses), tourist sites in Vancouver and China town (with maps), and asking for, giving, and following directions. Student worksheets and instructor notes are included. Most materials must be gathered by the instructor, using brochures, pamphlets, or tape recordings. 
Dragman, J., \& Hinkle, A. (1985). Airport customs and immigration. Community Survival Skills Series. Vancouver: Vancouver Community College. 80 pages. $\$ 7.50$.

teacher guide; speaking and listening skills; illustrations

Activities in this teacher resource book are designed for adult students who are landed immigrants in Canada: to familiarize them with Canadian custom regulations, with a special section on crossing the Canada-U.S. border by bus or car. Activity materials include flashcards, picture stories, and exercises. Dialogue scripts may be taped for classroom use.

Dragman, J. (1983). Using the health department: Health department services, child health centre, dental clinic home care. Community Survival Skills Series. Vancouver: Vancouver Community College. 104 pages. $\$ 5.00$.

life skills and community resources; regional; illustrations

Information and activities in this book concern Vancouver area health services. Dialogues, comprehension questions, picture stories, flash cards, and extension activities are included, and brief instructor notes appear throughout. The content is divided into Health department services, Home care, Child health centre, and Dental clinic.

Elrick, T. (1981). (rev. ed. 1991). Forms in your life: A student workbook and guide to everyday forms. Toronto: Globe/Modern Curriculum Press. 92 pages. $\$ 10.85$.

ESL literacy; blank forms

A wide variety of commonly used forms are reproduced along with vocabulary explanations and "hints and helps". Examples 
include banking forms (including deposits, withdrawals, and mortgage and loan applications), as well as application forms (for S.I.N., jobs, union membership, driver's licence, insurance, and credit cards). Special vocabulary and "hints and helps" are listed before each form. A list of abbreviations and a printing chart are included, and a record card is provided on the back cover. In some cases instructions are directed to school-age learners, but the content is generally suitable for adult learners. Some forms, such as the 1980 income tax return, may be dated.

Elson, N. (Ed.). (1983). Teaching English to adults: Methodology. Special issue of TESL talk, 14(1 \& 2). Toronto: Ontario Ministry of Citizenship. 249 pages. $\$ 5.00$.

teacher reference; annotated bibliography

Twelve chapters focus on characteristics of teaching and adults' learning of ESL, the teaching of specific language skills, and materials development. Each chapter is preceded by questions that introduce ideas to be considered in teacher education or initial preparation courses. A list of related readings for each chapter is included.

Employment and Immigration Canada. (1989). How to find a job in today's market. Ottawa. Hull: Employment and Immigration Canada. 52 pages. Free.

life skills; English for work; questionnaires; samples of letters, memos

The booklet provides information and strategies on how to find a job in both English and French. It is designed as a self-help booklet in which the reader is guided by questions and notes. Answers and suggestions are offered. In addition samples of cover letters, resumes, introductory letters to ads, and what to say on the telephone are provided. 
Employment and Immigration Canada. (1991). Canada: A Source book. 361 pages. A Newcomer's guide to Canada. 85 pages. Working with newcomers. 159 pages. Getting started in Canada. 12 pages. Ottawa: Employment and Immigration Canada. Free.

life skills; citizenship; teacher and student guide

The series consists of four documents that are designed to help immigrants learn about Canada as they learn one of Canada's official languages and as they adapt to, settle, and integrate into Canadian society. Canada: A Source book and Working with newcomers are informational resources for second language teachers, immigrant settlement workers and others who assist immigrants in their settlement and integration. These publications, which have the hierarchy of needs as their organizing principle, cover topics ranging from basic survival needs to personal aspirations.

Canada: A Source book is a syllabus designed to assist secondlanguage teachers plan the content of their LINC classes and to assist settlement workers plan orientation and information sessions. Information is presented in a Question and Answer format from the point of view of the immigrant. Each section is introduced by a question that invites immigrants to talk about customs in their source country and to learn about customs in Canada, thereby involving them in using the language and concepts being learned to express what is familiar to them. This publication also contains information about immigration, Canadian history, geography, culture, family structures, education, employment, religion, laws and the legal system, banking, transportation, multiculturalism and citizenship.

Working with newcomers presents a conceptual framework for people who offer orientation, information and services to 
newcomers. It is designed to provide an appreciation of the immigrant experience and suggests how Canadians can help newcomers during their adaptation, settlement and integration. Information is provided from a national focus related to the commonalities that Canadians share regardless of where they live in Canada. It is designed to be supplemented by community, municipal and provincial information sources.

A Newcomer's guide to Canada and Getting started in Canada offer information to newcomers. They are designed to help newcomers learn about Canada and the commonalities that Canadians share and cover, in condensed format, the same topics as those addressed in Canada: $A$ Source book.

Froese, M. (1983, rev. ed. of Yildiz, N. (1981)). Exploring downtown Vancouver contact: Teacher's guide (rev.ed.). Vancouver: Vancouver Community College. 123 pages. $\$ 9.00$.

life skills and community resources; speaking/conversation; regional; illustrations; maps

Designed to provide ESL students visiting Canada with contact with native speakers in natural language learning experiences outside the classroom, this program prepares students for reaching destinations in downtown Vancouver. In-class work on grids and mazes, tape-recordings of conversations, and feed-back sessions are some of the ways that language is analyzed or practised. The guide includes students' notes (some in Japanese), as well as descriptions of classroom and field trip activities.

Giacomelli, E. (1981). Guided writing for ESL learners: Unit 1 (rev. ed.). 29 pages. (1980). Guided writing for ESL learners: Unit 2. 38 pages. Vancouver: Vancouver Community College. $\$ 2.50$. 
ESL literacy; grammar; illustrations

The first unit focuses on developing adjective, time, and "because" clauses through answers to wh- questions about picture stories. Pre-writing activities are emphasized to integrate spoken understanding of syntax, structure, and vocabulary with written work. The second unit is designed to stimulate free composition. Sentence-level exercises focusing on wh- questions begin the unit; three guided composition "packages" follow emphasizing grammar points and sentence-combining.

Gillett, J., \& Goodfellow, G. (1990). The Canadian Oxford intermediate atlas. The Canadian Oxford intermediate atlas activity book. 48 pages. Don Mills, Ontario: Oxford University Press. Atlas $\$ 20.00$; Activity Workbook $\$ 10.00$.

ESL literacy; life skills; maps; scales; exercises

The activity book is designed to be used with the atlas. Questions and exercises on each map help students develop skills needed to understand and interpret various types of maps. Scales, graphs, lines of latitude and longitude, the compass, colours, symbols and climate are some of the many topics covered. Canada, along with other regions in the world, is focussed on. Fifteen reproducible outline maps appear at the back of the activity book. 
Heffernan, H. (1991). Garbage crisis: Environmental issues for adult ESL learners. Toronto: Toronto Board of Education. 59 pages. $\$ 15.00$.

Life skills and community resources; vocabulary; exercises; illustrations; pamphlets

This five-unit module designed for intermediate students addresses four questions about household garbage in Toronto: what it consists of, where it goes, where it comes from and what is being done to reduce, reuse and recycle. Each unit begins with questions for discussion, followed by a variety of vocabulary, language and problem-solving activities, along with activities for outside classroom work. The module includes pamphlets containing information on the environment and a list of places to obtain further environmental information in Ontario.

Hinkle, A. (1983). Applying for unemployment insurance: Using human resources. Community Survival Skills Series. Vancouver: Vancouver Community College. 66 pages. $\$ 7.50$.

ESL literacy; life skills and community resources; illustrations

The vocabulary and forms associated with job loss, and UI and GAIN applications are introduced. Notes for instructors highlight relevant information, procedures, and teaching techniques. Reproductions of real forms are included. Picture stories and other activities are designed for two levels of beginners.

House, J. (1983). Using the telephone for emergencies: Reporting a medical emergency, reporting a crime, reporting a fire. Community Survival Skills Series. Vancouver: Vancouver Community College. 77 pages. $\$ 7.50$.

life skills and community resources; regional; illustrations 
Separate sections include information and exercises on reporting medical emergencies, crimes, and fires. These are prefaced by a basic dialogue for telephone use in an emergency (911 and a request for a translator). Flashcards, dialogues, comprehension questions, situations, picture stories, and brief instructor notes are included.

House, J. (1986). Banking: An ESL workbook. Community Survival Skills Series. Vancouver: Vancouver Community College. 74 pages. $\$ 7.50$.

life skills and community resources; vocabulary; illustrations

Sections describe the layout of facilities in a bank, opening a new bank account, savings accounts, chequing accounts, using a bank machine, and applying for a loan. New vocabulary is introduced through picture stories, dialogues, and short reading passages. Black and white photographs and reproductions of forms are included.

House, J., \& Rabinowitz, M. (1986). Post office. Community Survival Skills Series. Vancouver: Vancouver Community College. 72 pages. $\$ 7.50$.

life skills and community resources; vocabulary; illustrations

Sections describe the layout of facilities in a post office, mailing letters and parcels, and other postal services, with exercises on specific aspects of each such as addressing envelopes, registering mail, and arranging delivery notices, change of address, and money orders. Vocabulary used in these situations is introduced by picture stories, dialogues, and short reading passages. Reproductions of forms are included. 
Hynes, M. \& Baichman, M. (1989). Breaking the ice: Basic communication strategies. White Plains, N.Y.: Longman. 90 pages. Book/Cassette \$43.50.

speaking/conversation; audiocassettes; exercises; illustrations; charts

Fourteen units help students develop listening, speaking, and conversation management strategies in situations such as small talk, asking for explanations, or expressing preferences. Units include discussion, pre-listening, listening comprehension, and guided conversation tasks, emphasizing meaningful, functional interactions.

Jibodh, C., Johnson, T., May, C., \& Smith, D. (1983). ESL resource book: Upper beginner's level. 173 pages. (n.d.). ESL resource book: Lower beginner level. 143 pages. Jibodh, C., Allen, C., \& Kennedy, P. (1985). ESL resource book: Grammar: Pre-intermediate-lower intermediate level (rev. ed.). 132 pages. Jibodh, C., \& Allen, C. (1987). ESL resource book: Grammar: Upper intermediate level (rev. ed.). 153 pages. Vancouver: Vancouver Community College. \$14.95.

general language study; grammar; series; illustrations; answer keys

These resource books are for teacher and student use. The beginner level books are organized by skill, and sub-divided by themes, such as consumer affairs (for communicative skills) and special days (for reading skills). The content guide crossreferences grammar activities to the theme-related activities. In the intermediate level books, grammar exercises are prefaced by notes on form and use. Contents include present perfect, modals, infinitives of purpose, adverb clauses, and adjective clauses among others, in the first book, and past perfect, passive voice, wish/hope, gerunds and infinitives, and noun clauses, 
among others, in the second book. Answer keys are published separately.

Johnson, M. (1982 rev. ed.). Foundation for literacy: Part one. (1978 rev. ed.). Part two. $56+48$ pages. Price: $\$ 4.95$. (1977 rev. ed.). Building the foundation: $A$ basic literacy course, The instructor's handbook. 21 pages. Winnipeg: Clarity Books. \$4.95.

ESL literacy; vocabulary; tests

The teacher's manual explains spelling instruction, focussing on either sound or orthographic patterns, along with teaching sound combinations, silent letters, and irregular consonants to more proficient students. The student's books include sentence completion and pronunciation exercises, and lists of words organized by common sounds.

Kehoe, J. (1984). A handbook for enhancing the multicultural climate of the school. Vancouver: Western Education Development Group, University of British Columbia. 93 pages. $\$ 16.95$.

teacher reference; anti-racist education; charts; illustra-tions; appendices

This practically-oriented handbook sensitizes teachers and others working in education to cross-cultural issues such as racism, values and practices of specific cultural groups, and biases in educational materials or tests. Various questionnaires, checklists, and recording instruments are provided to assess multicultural needs, provide for equality of opportunity, and develop appropriate curricula or attitudes in schools and communities. A conceptual framework is outlined to remediate students' prejudiced thinking. 
Klassen, C., \& Robinson, J. (1992). An approach to ESL literacy assessment. New Westminster, B.C.: Douglas College. 37 pages. Price not available.

teacher reference; ESL literacy; assessment; bibliography

This document outlines an approach to ESL literacy assessment using the interview as an assessment tool. Following the introduction which outlines the assessment purpose and rationale, the authors provide suggestions for implementing the approach. A chart of the assessment process is presented with each component described in step-by-step fashion. Probing techniques are offered for helping learners and assessors identify needs/goals, perceptions, abilities and strategies, and to develop learning priorities. Four appendices provide assessors with lists of topics to discuss, life goal areas, suggested materials to gather and specific skills to focus on. The fifth appendix includes a chart to record information.

Lee, E. (1985). Letters to Marcia. Toronto, Ont.: Cross Cultural Communication Centre. 71 pages. \$11.95.

teacher reference; anti-racist education; illustrations

This is a teacher's guide to anti-racist education. The four chapters each contain four sections which focus on describing anti-racist education, the school and community, the curriculum and student services. Chapters include letters, staff development notes and activities, classroom activities and resources.

Liebman, D. (1987). Canadian dictionary for English learners. Don Mills, Ontario: Addison-Wesley Publishers. 360 pages. $\$ 10.30$.

vocabulary; illustrations 
In addition to definitions of words written in simple English for ESL learners, this dictionary includes a pronunciation key, idioms, a list of irregular verbs, common abbreviations, numbers, punctuation marks and metric symbols. Several illustrations appear on every page to accompany word entries.

Loughrey, T., \& Smith, D. (1979). Contact. Vancouver: Vancouver Community College. 169 pages. $\$ 9.00$.

teacher reference; speaking/conversation skills; regional; bibliography; charts

The "contact approach" emphasizes language learning through interaction with native speakers of English. In-class guests and field trips, as well as individual and class activities, stimulate awareness of natural English use. The program was designed for groups of Japanese students visiting Vancouver, but the material can be used with students of any cultural background. Sample lessons are given for ESL as well as content-area learning. Students' and teachers' functions are described.

Magahay, W. et al. (1991). Meeting the needs: A preliminary assessment of ESL program delivery to adult immigrants/ refugees in Canada and a model towards language education for participation. Toronto: TESL Canada. 89 pages. $\$ 25.00$.

teacher reference; bibliography

This report based on a review of research, literature and unpublished documents outlines the history of ESL teaching in Canada and provides an assessment of the extent to which existing ESL programme delivery meets the needs of adult immigrants and refugees in Canada. In addition, recommendations for future policy and planning are made. 
Maldonado, D. (1990). Finding a place to live: Listening activities for adult ESL learners. Toronto: Toronto Board of Education. 32 pages. $\$ 15.00$.

Life skills and community resources; vocabulary; exercises; audiocassette

The six sections of this module provide opportunities for adult ESL learners to acquire the necessary language and knowledge to look for accommodation independently. Pre-listening activities introduce housing vocabulary in preparation for the seven conversations between landlords and potential clients. Activity sheets accompany the conversations as well as follow-up practice activities. Exercises focus on questions to ask landlords, directions, map reading, want ad vocabulary and telephone skills. A resource list is included naming community agencies and government offices providing information on housing and tenants' rights.

Manitoba Education and Training. (n.d.). Welcome news. Manitoba: Manitoba Education and Training. Free within Manitoba.

ESL literacy; citizenship; life skills; newspaper; photographs; illustrations; teacher notes

Published quarterly, Welcome news contains articles on issues relevant to Manitoba and Canada. As the audience is intended for ESL readers, articles are graded according to vocabulary and sentence structure. The content covers topics such as housing, employment, health care, government, multicultural events and sports. The teacher notes accompanying this newspaper provide activities and further information about the content of the paper. 
McKay, I. (1993). Beginning interactive grammar. Boston, Mass.: Heinle \& Heinle Publishers. 281 pages. \$24.95.

ESL literacy; grammar; exercises

Simplified grammatical explanations and examples are presented, along with a variety of practice activities. Practice includes such activities as open-ended, information gap and traditional (fill in the blanks, controlled practice) type activities. Simple readings are also provided, followed by activities. The use of North American idioms and vocabulary is evident in the activities.

Mohan, B. (1986). Language and content. Don Mills, Ont.: Addison-Wesley. 143 pages. $\$ 28.47$.

teacher reference

Mohan develops an educational model that integrates language and subject matter instruction across the curriculum, providing guidelines for education policy and teaching practices. The inter-relatedness of students' background knowledge and practical activity is shown through pairs of "knowledge structures" that reflect common elements of language, text organization, and thinking (Description/ Classification; Sequence/Principles; Choice/Evaluation). Both classroom and theoretical issues are explored in each chapter. Exercises and suggested readings are included.

Mollica, A. (1986, 1988). Word picture posters series. Welland, Ont.: Editions Soleil Publishing, Inc. \$3.50 each.

vocabulary; colour posters 
Vocabulary associated with holidays, places, activities, transportation, clothing, and food are illustrated on thirteen 18" x 24" posters. About twenty pictures appear on each poster, each one depicting a separate word relating to the theme.

Mollica, A. (1992). A Picture is worth 1000 words. Welland, Ontario. Editions Soleil Publishing Inc. 60 pages. $\$ 29.95$.

general language study; photographs

The book includes 60 photographs by North American photographers. Each photograph may be photocopied for classroom use.

Multiculturalism and Citizenship of Canada. (1990). Resource guide: Eliminating racial discrimination in Canada. Ottawa: Multiculturalism and Citizenship Canada. 16 pages. Free.

teacher reference; anti-racist annotated bibliography; addresses French/English

The guide includes references categorized under the headings of General, The Workplace, Education, Media, Municipal, Police, Justice, Audio-visual materials. Lists and addresses of advocacy groups in race relations appear at the end of the guide.

Ogelsby, N. (1992). The Ogelsby verb disc. Markham, Ontario: Pippin Publishing Ltd. \$5.95.

grammar

The Verb Disc includes 99 irregular verbs, numbered and alphabetized. Students can see all forms of the verbs through the "windows" on the front of the $25 \mathrm{~cm}$. diameter laminated disc. 
Ontario Ministry of Citizenship (n.d.) A bibliography of informational pamphlets and brochures. Toronto: Ontario Ministry of Citizenship. 47 pages. Free.

teacher reference; annotated bibliography; addresses

The booklet is a comprehensive listing of pamphlets and brochures which describes programs and services offered by government and agencies to help newcomers integrate and adapt to Ontario. Over 300 items are included, many of which are available in several languages.

Ontario Ministry of Citizenship. The Ontario times. Toronto: Ontario Ministry of Citizenship. Free within Ontario.

ESL literacy; citizenship; life skills; regional; newspaper; photographs; illustrations

Published by the Ontario Ministry of Citizenship seven times a year, October to April, The Ontario times contains articles on topical issues relevant to Ontario and Canada. Articles are graded for both beginner and intermediate students. As the intended audience is adult immigrants and refugees, much of the content deals with orienting readers to Canadian culture, customs and practices. This informative newspaper covers such topics as housing, employment, health care, government, multicultural events and sports.

Ontario Ministry of Citizenship. (rev. ed. 1992). Adult ESL: An annotated list of useful ESL books for teachers of adults. Toronto: Ontario Ministry of Citizenship. 60 pages. Free within Ontario.

teacher reference; bibliography; publishers list

GENERAL 
Recommendations by teachers and staff of the Citizenship Development Branch shaped this list of books for adult ESL. The annotated entries are organized by theme into 18 categories including professional development, class texts, variety of skills, literacy, songs, films, TOEFL, kits, and computers. Annotations are brief, focusing on purpose and scope of the materials, and include 1987 prices. Selections are listed in alphabetical order by title within each category.

Ontario Ministry of Citizenship. (1987). Themes and tools for ESL: How to choose them and how to use them. Toronto: Ontario Ministry of Citizenship. 41 pages. $\$ 2.00$.

teacher reference; adult curriculum \& instruction; illustrations

This booklet helps teachers to identify content that is relevant and meaningful to adult ESL students. Ideas are listed for choosing themes and involving students in creating and using tools. The FIGS principle (familiar, involves, generates, social setting) guides selection of themes and learning tools.

Ontario Ministry of Citizenship. (1988). Materials and services. Toronto: Ontario Ministry of Citizenship. 49 pages. Free within Ontario.

teacher reference; community resources

This booklet lists resources produced, collected, and distributed by the Ontario Ministry of Citizenship for ESL teachers, learners, and programs. Most entries are annotated. Information about associations, government offices, and grants is included. Instructions for buying or borrowing the materials are given. 
Ontario Ministry of Citizenship. (1988). Towards participation: A sample citizenship lesson plan. Toronto: Ontario Ministry of Citizenship. 48 pages. $\$ 3.00$.

teacher reference; citizenship; curriculum \& instruction

Adults in citizenship courses are taught "how to beat city hall" in this sample lesson plan based on an actual news article. A series of activities introduce vocabulary and explore the issue, relating it to personal experiences. Materials, grouping, processes, outcomes, and time frames of each activity are described; additional comments clarify aspects of the activities. Sample class handouts are included.

Ontario Ministry of Consumer and Commercial Relations. (1985). Insurance. Toronto: Ontario Ministry of Consumer and Commercial Relations. Free within Ontario.

life skills; regional

This kit contains one poster, 20 copies of illustrated newsprint tabloids, 4 activity sheets for duplication, 2 sets of 2 photo sequence stories, 1 leader's guide, 1 audio cassette with script, and 3 booklets. These materials introduce the concept of insurance in Canadian society while providing practical language practice.

Ontario Ministry of Citizenship. (n.d.). Ontario ethnocultural profiles. Toronto: Ontario Ministry of Citizenship. Free within Ontario.

teacher reference; anti-racist education 
This booklet consists in a series of sixty-six profiles of Canadian ethnic groups. Each profile is accompanied by relevant statistics and historical trends pertaining to immigration in Ontario.

Ontario Ministry of Education. (1990). English as a second language: Developing non-credit courses for adults. Toronto: Ontario Ministry of Education. Free.

teacher reference; bibliography; resources; appendices

This booklet provides information and references and makes suggestions for developing a program for adult ESL learners. Included also is an annotated bibliography of resources for adult ESL programs. A student profile form, needs assessment questionnaire and course evaluation questionnaire are included in the appendices.

Ontario Ministry of Transportation. (1990). Ontario driver's manual adapted for adult new readers. Toronto: Ontario Ministry of Transportation. 43 pages. Free.

life skills; ESL literacy; regional

This book is an adaptation in large print of the Ontario Driver's Manual for adults at a low-intermediate level of proficiency.

Phelan, F. (n.d.). Your news: Canada's teaching newspaper. Montreal: Your News. \$13.00.

ESL literacy; citizenship; life skills; newspaper; photographs; illustrations

Published 10 times per year, except for July and August, Your news contains articles on issues relevant to Canada and Quebec. As the intended audience is adult ESL learners, articles are graded for both beginner and intermediate students. This 
informative newspaper covers such topics as multicultural events, sports, government, health and housing.

Pierce, K. (1984). Insurance: An English as a second language workbook for beginners. Community Survival Skills Series. Vancouver: Vancouver Community College. 84 pages. $\$ 5.00$

life skills; regional; vocabulary; illustrations

The vocabulary and purposes for property, life, and car insurance are outlined and introduced in picture stories, dialogues, and exercises. Some references to ICBC (in B.C.) appear in the car insurance section.

Pietrusiak Engkent, Lucia, \& Bardy, Karen. Take part: Speaking Canadian English. 2nd edition. Toronto: Prentice-Hall, Canada, Inc. 130 pages. Student book $\$ 13.50$ (net to schools); Instructor's Manual \$22.00; Audio cassette $\$ 30.00$.

speaking/conversation; index cross-referencing Culture Notes and language.

New activities promote discussion in pairs and groups; units contain a wide variety of dialogues, discussion topics, activities and assignments. Culture Notes talk about Canadian life; Language Notes expand on features of pronunciation, usage and idiom.

Pinton, R., \& Strong, I. (1984). Let's get on with the job: A job search manual for the ESL classroom. Vancouver: Vancouver Community College. 341 pages. $\$ 18.95$.

life skills; English for work; annotated bibliography; illustrations 
Five modules on job search skills (self-assessment, preparing a resume, methods of finding jobs, application forms, and preparing for the interview) are divided into several lessons. Each module begins with notes to the teacher. Translations of vocabulary from application forms appear in 14 languages and of vocabulary from the want-ads in 11 languages. An annotated bibliography of pre-vocational resources is included.

Pitton, C. (1988). Find out: An interaction book for adults who are learning to speak English. Vancouver: Canada Language Centre. 81 pages. $\$ 18.65$

general language study; illustrations

Twenty-five units on a variety of situations, structures, vocabulary, and functions are graded according to language ability and focus on social interaction among students in adult ESL classes. Topics include jobs, prepositions, future (going to), household items and rooms, time expressions, and general mixers, among others. Each exercise allows students to review previously studied vocabulary and structures while mingling with other class members. Activities emphasize "finding someone who..." does, likes, or has a certain thing. Teaching and follow-up suggestions, reductions for overhead transparencies, and student activity pages are included.

Podoliak, E. (Ed.). (1988). Canadian ESL materials. Special issue of TESL Talk, 18(1). Toronto: Ontario Ministry of Citizenship. 236 pages. $\$ 5.00$.

teacher reference; figures; photographs; bibliographies; appendix

This volume offers 24 brief papers describing diverse aspects of ESL materials prepared recently in Canada, including reports on the use and development of exemplary materials; advice for teachers in creating materials related to their students' needs and 
experiences; the processes of getting materials published; simplification of reading texts; use of community resources; annotated bibliographies; distance education materials. An appendix lists the addresses of commercial ESL publishers and distributors in Canada.

Public Service Commission. (1991). Interface Canada. Student's Book 1-8. Teacher's Book 1-8. Role Play for Consolidation. Ottawa: Supply and Services Canada. Teacher's Book \$24.95; Student Book \$10.95; Audiocassette \$9.95.

general language study; speaking/conversation; audiocassettes; series; teacher's guide; illustrations; answer keys

The series consists of 8 student books, 8 teacher's books and a Role Playing for Consolidation book, with accompanying cassettes. The materials are designed to develop speaking and listening skills, with emphasis on language used in the office. Each Teacher's Book consists of pedagogical instructions, answer keys and the Student Book with cross-referencing. Each book covers approximately 50 hours of classroom instruction. A variety of techniques and texts appear throughout all books.

Rabinowitz, M. (1983). Sewing: An English as a second language workbook for beginners. Community Survival Skills Series. Vancouver: Vancouver Community College. 58 pages. $\$ 7.50$.

English for work; illustrations

Vocabulary associated with the sewing trade is introduced through picture stories, dialogues, and short reading passages. 
Reid, J., Adamowski, E., \& Brand, M. (n.d.). Getting started: A handbook for volunteer ESL instructors and their supervisors. Toronto: Toronto Board of Education. 142 pages. $\$ 30.00$.

teacher reference; teacher training

Designed to help volunteer ESL instructors, this handbook provides information on adult learning, classroom methodology and lesson planning. Specifically, it outlines important factors to consider when teaching adults, needs assessment techniques, ways to decide on course content and materials and ways to cope with multi-level classes. The handbook also offers supervisors suggestions on how to recruit, train, support and evaluate volunteers.

Rusque, R., \& Segal, L. (n.d.). English English English. Articles with countable nouns workbook. 28 pages. The Past Tense of Regular Verbs. 23 pages. Letter Dictation. North York, Ont.: North York City Centre. 31 pages. $\$ 10.00$ per module

grammar; general language study; answer key; audiocassettes

English English English is a series, consisting of three independent lessons, a workbook and an accompanying audiocassette. Workbooks provide exercises for practising various language skills. Additional exercises and an answer key are found at the back of each workbook. Each lesson includes 30 minutes of audio and 90 minutes of workbook practice.

Saskatchewan Literacy Network. (n.d.). On our way. Saskatoon: Saskatchewan Literacy Network. $\$ 40.00$.

ESL literacy; life skills and community resources; newspaper; photographs; illustrations; citizenship 
Published nine times a year, this newspaper features brief, simplified versions of major stories, stories of popular interest, and descriptions of social or government services. Articles are graded according to reading proficiency (easiest, harder or general). The articles are relevant to Saskatchewan and Canada.

Selman, M. (1991). Adult ESL program evaluation guide. Victoria: Ministry of Advanced Education, Training and Technology and the Centre for Curriculum and Professional Development. 73 pages. $\$ 7.80$.

teacher reference; program evaluation; questionnaires; bibliography

This guide outlines approaches and criteria to evaluate ESL programs. The introduction describes purposes of evaluation, procedures and suggestions for interpreting evaluation results, with a brief bibliography. The rest of the document includes 23 Good Practice Statements which provide a standard for assessing ESL programs, along with questionnaires for each statement. Also included are a Learner Tally Sheet for summarizing the results of learner questionnaires, a Program Planning Form for listing program objectives, and a Program Profile for describing the program and analyzing the services provided.

Selman, M., \& Mrowicki, L. (1984). A new start -- Canada: A functional course in basic spoken English and survival literacy. Teacher's book, student book, and 2 literacy workbooks. Agincourt, Ont.: Dominie Press \& Heinemann Educational Books. $259+148+132+104$ pages. Teacher's book $\$ 15.95$; Student book $\$ 10.95$; Workbook 1 \& 2 \$7.95; Cassette (4) $\$ 57.50$.

general language study; audiocassettes; teacher's book; student book; 2 literacy workbooks; illustrations; appendices 
Communicative skills are emphasized in these course materials for literate and non-literate adult students. Activities are organized by social functions, and divided into four sections. The first introduces basic skills that are expanded on in subsequent sections; a review and evaluation appears after each section. The teacher's book outlines objectives, materials, methods, and notes for alternative activities, including a transcription of recorded material for each unit. Appendices analyze the course content in chart form, illustrate the characters that interact in the activities, and list recommended visual aids, survival literacy vocabulary, and sound/symbol relationships.

Sims, J. (Ed.). (1990). Education systems of immigrant students. North York: North York Board of Education. 50 pages. $\$ 5.00$.

teacher reference

Educational systems of countries around the world are described under the headings of education system, placement/program suggestions, curriculum, school year, discipline and attendance, background, language and names. Sketches of religious beliefs are also included at the back of the booklet. Maps outline the educational systems of the U.S.S.R., African, European and Asian countries.

Spears, R., Schinke-Llano, L., Kirkpatrick, B., \& Fongemie, N. (Eds.). (1984). Everyday Canadian English dictionary: A basic dictionary for English language learning. 394 pages. SchinkeLlano, L., Spears, R.A. \& Fongemie, N. (1985). Everyday Canadian English dictionary: Workbook and Answer key. 40 pages. Toronto: Copp Clark Pitman. Dictionary \$13.69; Workbook $\$ 9.38$.

vocabulary; tables 
The organization and content of this dictionary have been simplified for use by ESL learners. Basic dictionary information is stressed. There are separate entries for irregular past tenses, past participles, and contractions. Simple grammatical and lexical information and Canadiana are included. The workbook introduces dictionary skills, reinforcing their use through a variety of exercises.

Steinberg, J. (1983). Games language people play. Markham, Ont.: Pippin Publishing Ltd. 120 pages. Price: $\$ 11.95$.

teacher reference; illustrations; index

The 110 games in this book are organized by proficiency level and coded for language skills to be practised. Optimal group size, objectives, materials, and rules are given for each game, as are adaptations and suggestions. Games were selected for inclusion if they were easy to explain, inexpensive, uncomplicated, and versatile. Instructors are encouraged to adapt the games to the needs of their specific classes.

Stevens, S. (1991). Aids education for English language learners. Winnipeg, Manitoba: Planned Parenthood Manitoba, Inc. 179 pages. $\$ 20.00$.

teacher reference; life skills and community resources

This manual is a practical guide for ESL teachers planning to introduce the topic of AIDS in their classrooms. The content includes chapters on facts about AIDS and AIDS education, AIDS in a multicultural context, and roles of the ESL teacher in AIDS education. The manual closes with a series of appendices, including background readings, curricula, audiovisual aids, local and national organizations. Included also are planning and 
curriculum suggestions, along with exercises, diagrams and health vocabulary.

Tennant, S., \& Yildiz, N. (1980). Tea and talk party contact manual: Teacher's guide. Vancouver: Vancouver Community College. 129 pages. $\$ 9.00$

teacher reference; speaking/conversation; life skills and community resources: regional; bibliography; videocassette locally available

Preparation for a visit to a Canadian family's home is the focus of this guidebook; it extends the concept of language learning through natural encounters with native-speakers developed in Loughrey \& Smith (1979). In-class activities, include viewing a typical situation on a videotape and role-playing. The student information is translated into Japanese. A flow-chart of activities introduce the guide; page numbers and activities are cross-referenced throughout.

Thomas, B. (1987). Multiculturalism at work. Toronto: YWCA. 157 pages. $\$ 23.00$.

teacher reference; anti-racist education

This book focuses on how to expand and implement teaching programs and lessons, taking into consideration the multi-ethnic fabric of Canada. This book also discusses a series of common biases concerning race and background.

Thompson, M. (Ed.). (1981). Developing basic reading and writing skills: Beginner level (rev. ed.). Vancouver: Vancouver Community College. 40 pages. $\$ 3.00$.

ESL literacy; illustrations; teacher guide 
Phonics skills are the basis of this reading and writing program for adult beginner. Activities are organized by proficiency level and are prefaced by a suggested order for teaching. Teaching tips, descriptions of activities, and sample activity sheets are included.

Thompson, M., Jobodh, C., Smith, D., Johnson, T., \& Allen, C. (Eds.). (1984). Curriculum guide: English language training: Beginners and pre-intermediate level. 42 pages. Kennedy, P., Allen, C., \& Jobodh, C. (Eds.). (1984). Curriculum guide: English language training. Intermediate level. 15 pages. Thompson, M. (Ed.). (1980). Lesson ideas: English language training: Beginners level. 44 pages. Vancouver: Vancouver Community College. $\$ 5.00$ each level.

teacher guide; general language study; life skills and community resources; series; teacher guide

In the beginning level of this series, listening to and speaking everyday English are emphasized, while reading and writing receive attention at the pre-intermediate level. The communicative objectives at each level are organized by theme (i.e. Family/Self, Social needs, Consumer affairs). Structural objectives are stated in lists of parts of speech; writing and reading objectives are stated as lists of skills or tasks. The sections are cross-listed with suggested topics. Activities are described by objectives, procedures, materials, follow-up, and additional notes.

Thompson, M., \& Williams, S. (1979). Stories for beginners: Books 1, 3, 4. $14+20+16$ pages. Flack, G., Thompson, M., \& Williams, S. (1979). Stories for beginners; Book 2. 15 pages. Thompson, M. (n.d.). Stories for beginners...with related exercises. 24 pages. Vancouver: Vancouver Community College. $\$ 1.95$ each. 
ESL literacy; vocabulary; illustrations

The first two books each follow one character through his and his family members' daily activities. The other books focus on several characters, members of an ESL class and their teacher, who tell of a personal event. The brief stories (5-10 sentences) are followed by word lists for vocabulary practice. The first book includes notes to the teacher on presenting vocabulary through flashcards, reading aloud, follow-up activities, and phonics. In Stories for beginners... with related exercises, a list of new vocabulary, and exercises focusing on word structure, meaning, sound, and use follow each story.

Toronto Board of Education. (1992). ESL or ESL literacy? Toronto: Toronto Board of Education. 163 pages. Package $\$ 65.00$; Manual $\$ 45.00$.

ESL literacy assessment; manual; videocassette

The assessment tool is designed to assess literacy skills of people in their first language (not English). Part 1 of the manual explains and describes the components of the assessment tool: the interview, the writing and reading assessments and the kit. Part 2A includes the contents: the Learner Profile Interview form, the Writing Assessment form, the text to assess reading and reading assessment questions. Part $2 \mathrm{~B}$ contains the assessment kits by languages (e.g. Amharic, Arabic, Chinese, Urdu -- seventeen languages in total). A video which focusses on interviewing techniques accompanies the manual.

Toronto Board of Education. (1991). Anti-racist education and the adult learner. Toronto: Toronto Board of Education. 55 pages. $\$ 8.00$.

teacher reference; anti-racism 
This handbook is divided into 3 parts. Part 1, Issues and Initiatives, provides background on the nature of racism and outlines initiatives taken by governments and the Toronto Board to address racism. Part 2, Responding to Racist Behaviour, contains suggestions for dealing with racism. Part 3, Anti-Racist Education, gives and overview of anti-racist curriculum. A glossary, bibliography and lists of government and community resources appear at the end of the handbook. Included also are scenarios ad activities which can be used in the classroom.

Toronto Board of Education. (1991). Community contact assignments. Toronto: Toronto Board of Education. 52 pages. $\$ 15.00$.

teacher reference; general language study; life skills and community resources; lesson plans

This booklet provides guidelines for developing community contact assignments, characteristics of a good assignment and states the benefits of community contact assignments. Also included are four sample lessons, along with suggested destinations.

Toronto Board of Education. (1990). Incorporating an intercultural perspective into the ESL curriculum. 45 pages. $\$ 15.00$.

teacher reference; citizenship; lesson plans; teacher's guide

Included in the handbook is an integrated approach to language and culture in the curriculum. Five lessons which promote the development of intercultural awareness are presented as samples. Topics for discussion and a list of references appear at the end of the handbook. 
Toronto Board of Education (rev. ed. 1992). Learning materials for the Adult learner: An annotated catalogue of useful Adult ESL and literacy materials for teachers and students. Toronto: Toronto Board of Education. 23 pages. Free.

teacher reference; bibliography

The annotated entries are organized into categories including ESL learning modules, ESL learner's stories and activities, literacy materials, reports and discussion papers. Annotations are brief, focusing on purpose, scope and level of the materials. Prices are also included.

Toronto Mayor's Committee on Community and Race Relations. (1991). Myths and facts. Toronto: Toronto Mayor's Committee on Community and Race Relations. 25 pages. $\$ 1.00$.

teacher reference; anti-racist education

This booklet presents numerous myths surrounding race relations, immigration, refugees, multiculturalism and employment, and challenges them with factual information. A glossary is included, defining such terms as racism, race relations, prejudice, bias, multiculturalism, refugee claimant, settlement programs and employment equity.

Warren, C. (1986). Vignettes of life: Experiences and self perceptions of new Canadian women. Calgary: Detselig Enterprises. 128 pages. $\$ 10.95$.

teacher reference; ESL literacy; bibliographies

The life stories of 17 women who have recently immigrated to Canada from different parts of the world are presented as brief narratives documenting their lives in their native countries, their 
lives in Canada, and their future plans. These vignettes are prepared from in-depth interviews with the individuals. An introductory chapter analyzes common themes in the life stories. Bibliographies cite related readings on women's issues, acculturation, self-concept, and media resources.

Watson, B. (Ed.). (1980-1983). English language training: Night school department: Workshop series, Nos. 1-9. Vancouver: Vancouver Community College. $\$ 1.00$.

teacher reference; series; videocassette available locally

The 9 workshops described in this series orient novice ESL teachers to: "Stress, intonation and other phonological areas", "Teaching techniques", "Faculty or instructional evaluation", "Pre-vocational English", "More teaching techniques", "Winging it", "Field trips", "Job search skills", and "Still more teaching activities". This series is practically-oriented, including exercises of activities and some class handouts Vocabulary for specific purposes features in most exercises and activities.

Weber, K. (Ed.). (1978). The globe modern dictionary. Toronto: Globe/Modern Curriculum Press. 1267 pages. $\$ 18.50$.

vocabulary; appendices

This simplified dictionary, rather than using codes, symbols, or abbreviations, writes parts of speech in full, uses familiar language sounds in the pronunciation guide, not phonetic symbols, and gives examples to clarify idiomatic meanings. American spellings are used as headwords, with alternative spellings entered next. Following definitions and uses, a "word family" entry shows other forms of the word. Appendices include geographical and political information about Canada, the 
United States, and the world The inside covers display and define the parts of the dictionary entries.

Weber, K. \& Weber, C. (1987). World of vocabulary Canada, 128 pages. \& (1988). Challenge of vocabulary Canada, 128 pages. Toronto: Globe/Modern Curriculum Press. \$10.85 each.

ESL literacy; vocabulary; illustrations; dictionary

Vocabulary and pronunciation are highlighted in 20 brief readings on Canadian people, places, animals, and events in each book. Following the reading passages are exercises in reading comprehension, and selected aspects of the vocabulary, such as alphabetical order, definition, sentence completion, word games, story completion, and discussion or research. A vocabulary list with definitions is included.

Weinstein, N. (1992). Reading snacks: A reading/conversation text for low-intermediate students. Toronto: Maxwell Macmillan Canada, Inc. 100 pages. $\$ 16.95$.

ESL literacy; speaking/conversation

This consists of an introduction to five popular fictional genres: mystery, science fiction, romance, western, and horror. Each short fictional excerpt is accompanied by pre-reading questions and followed by a set of exercises to develop oral and writing skills. Students are always encouraged to invent a conclusion for some of the stories.

Williams, E. (1988). Pronunciation curriculum for beginning and intermediate students of English as a second language. Vancouver: Vancouver Community College. $\$ 3.00$.

speaking/conversation; audiocassette; teacher guide 
Five levels of student pronunciation exercises are colour-coded, and include two sets of lessons at each proficiency level. Number and letter coding indicates the level, the lesson, and whether the material is new, review, or alternate. Aural/oral exercises are based on Canadian English using a simplified system of signs and symbols to represent sounds. Lessons incorporate spelling and dictionary skills where relevant. A list, audiocassette, and examples of Canadian English vowels are included in the Instructor notes.

Wong, A. (1988). Practical English for new Canadians. Vancouver: Vancouver Community College. 78 pages. $\$ 5.00$.

life skills; vocabulary; videocassette available locally

The 39 lessons include a brief dialogue on a specific theme of everyday life, followed by useful words and phrases, and a practical activity. Themes include using the telephone, ordering meals, talking to teachers, doctors, dentists, and pharmacists, renting or buying a home, banking, and using community services and facilities.

Wong, L. (\& Thompson, M. (Ed.).). (1987). I remember.... Vancouver: Vancouver Community College. 33 pages. $\$ 3.50$.

ESL literacy; illustrations

Wong reminisces about his childhood in Canton sixty years ago. Memories of his father and mother, his teachers and education, are told in straightforward English, concluding with a story of "the old man and the mountain", by which he lives his life.

Wurtele, B. (n.d.). We just don't speak English, 7 vols. Waterloo, Ont.: English in the Working Environment. 51 pages per vol. $\$ 1.50$. 
life skills; citizenship; multi-lingual; illustrations

These handbooks introduce survival English for Canada. There is one volume in English and one volume in each of Laotian, Hmong, Chinese, Spanish, Vietnamese, and Portuguese. Topics include: Canadian geography and citizenship, transportation, telephoning, health, shopping, banking, school, work, accommodation, and law.

Yalden, J., Fitzgerald, B., \& Pagurek, J. (1984). Frameworks for communicative needs courses. Introduction, 6 pages. Teacher's handbook, 35 pages. First step towards communication, 25 pages. Coping, 12 pages. Expressing basic concepts, 31 pages. Arriving at your destination, 18 pages. Getting around, 20 pages. At a hotel, 34 pages. Eating out, 22 pages. Shopping for food, 18 pages. Shopping (non-food), 22 pages. Using the telephone, 41 pages. Ottawa: Centre for Applied Language Studies, Carleton University. $\$ 20.00$.

teacher reference; life skills; vocabulary; speaking/conversation; materials, \& activities; illustrations

These 12 booklets are designed to assist teachers to plan instruction for adults learning initial, functional communication in a second language. Each booklet specifies learning objectives, cultural considerations, kinds of spoken transaction, useful expressions, and classroom activities (information gathering, information-sharing, information-processing, and role plays) as a framework for preparing lessons appropriate to learning to interact socially in specific situations in a new language and culture. These frameworks form a basis for teaching any language at the initial stages, requiring a teacher to provide materials, speech, vocabulary, and cultural background to implement a curriculum to suit learners' needs and interests. Use of the new language to transact information and perform

TESL CANADA JOURNAL/REVUE TESL DU CANADA 
social functions is emphasized in the objectives and suggested teaching activities.

Yildiz, N., Warren, B., \& Froese, M. (1981). Let's communicate; An ESL curriculum guide for young Japanese students (rev. ed.). 274 pages. Adams, K., \& Yildiz, N. (1980, rev. ed. of Yildiz, N., \& Tennant, S. (1979)). Let's talk: Developing effective communication skills: An EFL curriculum guide for Japanese high school and university students. 317 pages. Vancouver: Vancouver Community College. $\$ 22.00$.

teacher guide; speaking/conversation; bibliography; illustrations; games; regional; maps

Developed for an 8 to 10 day program for 8 to 15 year-old Japanese students visiting Vancouver, Let's communicate focuses on communicative English activities in and out of the classroom. In 8 topic areas (including Personal information/Social exchanges, Daily activities, Possible Problems, and Introduction to Canadian culture) the language objectives, materials, activities, and teaching points are described, with variations of activities given for 3 levels of beginning proficiency. Let's talk follows the same format and principles, but is designed for high school and university-aged students. Thematic units, such as Food, Shopping, and Living with a Canadian family are prefaced with a list of teaching objectives and activities. In both curriculum guides copies of handouts, workbook suggestions, and reduced copies of large aids are included. Pictorial stories about interesting people from B.C.'s past are featured.

Zuern, G. (1985). Images: English for beginners, Books 1 \& 2, and Teacher's ed. Don Mills, Ont.: Addison-Wesley. $86+84$ pages. Book 1 \$9.55; Teacher's Book 1 \$11.95; Cassette \$58.20; Book 2 \$9.90; Teacher's Book 2 \$11.60; Cassette $\$ 66.15$. 
general language study; teacher's manual; audiocassette

Communicative use of new vocabulary and structures is demonstrated in black-and-white picture stories, followed by a variety of short-answer and listening exercises. Each book has a word list, an answer key, and a skills index. Lesson plans for each chapter appear in the teacher's manual. Canadian place names are used in the exercises.

Zuern, G. (Ed.). (1978). The newcomers: Photo stories for learners of English. Toronto: Ontario Ministry of Citizenship. 20 pages. $\$ 1.00$.

general language study; ESL literacy; newspaper format; illustrations; answer key; teacher's guide

Six one-page photo stories show a Chinese family's adjustment to Canadian life; the facing page has fill-in-the-blank exercises based on the story. An activities section for each story suggests topics for small group discussions, and a review section ties the stories together. A reading section gives additional information about the topics introduced in each of the stories. 
Zuern, G. (Ed.). (1987). Sonia: Photo stories for learners of English as a second language. Toronto: Ontario Ministry of Citizenship. 27 pages. \$.50.

general language study; ESL literacy; newspaper format; illustrations; answer key

Nine photostories collected from the newspaper "Newcomer News" follow a new Canadian from South America and her family as she arrives in Canada, begins an English class, gets a job and an apartment, and goes Christmas shopping, among other activities. Instructions to the student appear in five languages: English, Italian, Portuguese, Spanish, and Chinese. Exercises in story comprehension, vocabulary, and sentence completion, as well as further information, follow each photo story. A review page and suggestions for use are included. 